\title{
Micro and Macro Structural Investigations on Welded Joints of Composite Truss Steel Concrete Beams
}

\author{
Silvia Caprili (D), Walter Salvatore, and Renzo Valentini \\ Department of Civil and Industrial Engineering, University of Pisa, Pisa, Italy \\ Correspondence should be addressed to Silvia Caprili; silvia.caprili@ing.unipi.it
}

Received 20 August 2020; Revised 5 January 2021; Accepted 9 March 2021; Published 25 March 2021

Academic Editor: Baozhong Sun

Copyright ( $\odot 2021$ Silvia Caprili et al. This is an open access article distributed under the Creative Commons Attribution License, which permits unrestricted use, distribution, and reproduction in any medium, provided the original work is properly cited.

\begin{abstract}
The results of an experimental test campaign including micro and macro investigations on welded joints typically used in Composite Truss Steel-Concrete beams are presented. The research was carried out with the aim of assessing the relevance of welding effects on the mechanical performance of different typologies of steel grades that can be used to realize the internal truss steel system, connected to the bottom steel plate used with the double structural and formwork function. Two different steel typologies were adopted for the steel truss: the "traditional" structural micro-alloyed steel, normally used for composite steelconcrete elements, and the typical reinforcing steel with TempCore ${ }^{\circledR}$ structure, achieved through the application of two-phase thermomechanical treatment of quenching and tempering. The interest in the possibility of adopting reinforcing steel for the internal truss arises from its potential economic benefit, finding its justification in the intermediate condition in which this structural typology lies, between composite steel-concrete and ordinary reinforced concrete buildings. Welding has a strong impact on such reinforcing steel material, resulting in relevant drops of ductility and brittle failure usually taking place in correspondence of the heat-affected zone. So, it is advisable to refrain from using such steel grade, especially in constructions in seismic-prone areas, where ductility is a major influencing and design factor.
\end{abstract}

\section{Introduction}

Modern design standards for buildings in seismic areas foresee the application of specific requirements and details concerning sections' dimensions, reinforcements' layout, and material properties. Actual Italian standards for constructions [1], in alignment with Eurocode 8 prescriptions [2], aim for the application of the well-known and consolidated capacity design approach for new buildings in seismic-prone areas. With the main objective of achieving a global ductile collapse mechanism, able to dissipate the energy stored in the building during seismic event, selected elements are devoted to plastic deformations' development. These dissipative elements differ, obviously, in relation to the structural typology of the building, being located at the ends of beams and first floor's columns in case of Moment Resisting Frame structures, in diagonal in tension in case of Concentrically Braced Frames or even in links in case of Eccentrically Braced Frames. The nondissipative members (including both elements and usually connections) are protected against plastic deterioration through a specific over-sizing keeping them in the elastic field.

The building ductility depends on the deformation capacity of elements, sections, and finally of the material itself: each of these terms is necessary, but not enough, to guarantee the achievement of the whole ductile behaviour, normally expressed in terms of ratio between ultimate and yielding displacement. In the case of reinforced concrete (RC) constructions, for example, the development of plastic deformations is expected in correspondence of beams' ends and, at last, at first floor columns' bases. The achievement of the ductile global mechanism is combined with the protection against brittle failures (e. g. shear forces) and, for each direction and sign of the horizontal seismic action, to the satisfaction of beams'/columns' hierarchy in correspondence of the joint. Specific rules for reinforcement details and restrictive indications about materials complete the framework of the capacity design approach. Similar 
considerations are also valid for composite steel-concrete structures; these last ones, according to D.M.17/01/2018 [1] and to Eurocode 8, are defined such as "constructions made up of steel and reinforced concrete (ordinary or prestressed) components cooperating through the introduction of a connection system opportunely designed."

Composite steel-concrete constructions can be designed to have a nondissipative or a dissipative behaviour: in the latter case, plastic deformations develop in composite steel/ concrete components or, otherwise, in correspondence of steel elements. In both cases, the dissipative regions shall develop where plastic deformations, local buckling, or other eventual degradation phenomena related to the cyclic/ seismic behaviour do not affect the whole structural stability of the building.

In the framework of steel-concrete composite constructions, a role of specific importance is played by Composite Truss Steel-Concrete (CTSC) beams. This structural typology spread across the Italian and international territory starting from the end of the 1960s, being patented by Eng. Salvatore Leone, in their first configuration known as REP ${ }^{\circledR}$ technology (acronym used for $R$-rapid, $E$-economic, and P-practical). Starting from REP ${ }^{\circledR}$ systems, since 2011, the marketing of the New Performance System (NPS ${ }^{\circledR}$ ) began: a construction system in mixed steel-concrete structure composed of columns, floors, and, specifically, beams. CTSC beams are composite steel-concrete elements able to cover large spans, easy to be in-situ assembles and provided by a good structural performance. The typical CTSC beam is characterized by the presence of a bottom steel plate having the dual function of formwork for the following concrete casting and of load-bearing component toward sagging bending moments. The bottom steel plate is welded to the steel truss constituting the reinforcement of the beam that, alternatively, can be incorporated into a RC prefabricated base that can protect the welded load-bearing structure against fire and to support the first phase loads of prefabricated floors.

Several studies in the current scientific literature were performed with the aim of investigating the structural performance of CTSC beams and RC columns, one of the most common solutions adopted worldwide $[3,4]$. From the structural point of view, several issues still exist concerning the effective behaviour of the abovementioned structural typology, dealing with the design rules that lie in a not well codified procedure intermediate between RC and composite steel-concrete constructions, the specific design and realization of beam-to-column joints with selected ductility performance, and above all the adoption of construction indications for materials and welding.

The structural behaviour of abovementioned constructions-mainly referring to joints representing the most critical aspect-is normally assessed in comparison to traditional RC solutions, finding the improvement in terms of strength and ductility and analysing the practical assembly aspects of the proposed systems. Results, globally highlighting the satisfaction of the minimum structural requirements, evidenced in the meanwhile several important aspects to account for when designing such typology of structure, concerning the design phase, the realization phase, and especially the steel material selection. In the present paper, the problem of the influence of different steel grades for the realization of the internal truss is addressed through a deep experimental investigation involving both mechanical and microstructural aspects. The main questions arise from the possibility of adopting the internal steel truss hot-rolled steels or, otherwise, reinforcing steels, especially in relation to the reliability of welding when applied to these steel typologies when, according to the design strategy for buildings in seismic prone areas, enough ductility (or, generally, deformation capacity) shall be provided.

\section{CTSC Beams and the NPS ${ }^{\circledR}$ System}

2.1. Main Features and Technical Issues. The wide diffusion of the NPS ${ }^{\circledR}$ (and, before, of REP ${ }^{\circledR}$ ) systems during the last decades for civil and industrial constructions, infrastructures like bridges, viaducts, etc., is due to their extreme easiness in the assembly phase, allowing to "couple" the CTSC beams (Figure 1) to the most common floor typologies (such as predalles, composite steel-concrete, cellular concrete, etc. [5]) and, at the same time, the possibility of covering high span length. CTSC beams are widely used in Italy being able to optimize construction times and owing a strong economic convenience respect to traditional systems. Trying to generalize, such beams represent the intermediate solution between the RC and the composite steel-concrete systems, characterized by some features of both structural typologies [4-6]. The problem, on the other hand, lies in the fact that the contours between RC and composite steel-concrete rules to follow are not well-defined, especially from a design point of view, resulting in several technical and design uncertainties that single producers-by their own-try to solve in the most convenient and efficient way.

Three main typologies of construction systems using CTSC beams can be nowadays identified. The first typology consists in CTSC beams and traditional RC columns or shear walls realized with "ordinary" concrete class C25/30 (or slightly higher) and "ordinary" reinforcing steel (i.e. grade $\mathrm{B} 450 \mathrm{C}$ for Italian regions according to actual standards). The second alternative consists in CTSC beams and precast high-strength RC columns (class C70/85); the last one, finally, employs CTSC beams and columns realized with steel tubes filled with concrete, avoiding the buckling problems typical of steel structures. Different typologies of CTSC beams exist, in relation to the adoption of a formwork made with steel or concrete, to the different use in constructions and infrastructures, etc.

The design of CTSC beams accounts for two different phases associated with different static schemes and corresponds to a different structural behaviour toward acting loads. In the first phase, a simply supported scheme is used for the beam corresponding only to the steel truss, since the concrete casting-even if already executed-has not still achieved the expected compressive strength. The bearing structure is then made up of the only steel components of the CTSC system: the bottom plate and the steel truss shall be checked against current standards $[1,2]$ and commercialized 

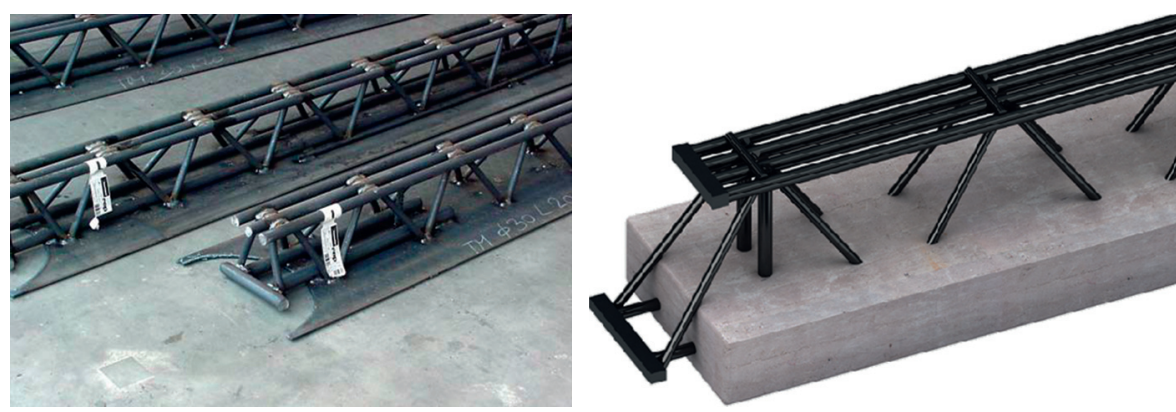

FIgURE 1: The two most common typologies of CTSC beams with steel and concrete formwork.

in agreement with rules of EN1090-1:2012 [7]. The first-step structure shall bear all the loads acting at this stage, including the weight of the steel structure, the dead load of the beam, the concrete slab, and the casting itself. RC columns (or, in case, shear walls or other vertical supports) are designed to withstand the resulting vertical loads. Once the curing of the concrete cast is completed, the resulting structure is, effectively, a composite steel-concrete beam, where perfect bonding is realized through the penetration of the concrete between the steel truss components. The static scheme, due to the presence of additional reinforcements located in correspondence of the two supports before the cast, allows the transmission of flexural/bending actions to columns or to adjacent beams. The second design phase follows the rules commonly adopted for composite steel-concrete structures, where shear forces shall be fully sustained by the steel components: in agreement with the actual standards $[1,2]$, the shear resistance of composite steel/concrete element needs to be fully provided by the steel part.

Specific attention shall be paid to the realization of the beam-to-column connections that shall guarantee the development of a global dissipative mechanism, assuring, in parallel, the transfer of actions to vertical bearing elements. This means that adequate local ductility shall be provided to connections, even if the practical realization of the system is not nowadays completely standardized. As widely presented by Amadio et al. [3], Amato et al. [8], Mazzotti et al. [9] and others, in the presence of seismic events and horizontal actions, beam-to-column joints in CTSC beams and RC columns can be subjected to high actions becoming the crucial components for the satisfaction of the capacity design philosophy. The most relevant issue is related to the difficulty in achieving the structural continuity within the joint: the introduction of additional reinforcements can be difficult and, in some cases, not easily realizable. Nowadays, connections between CTSC beams and columns at the floor level are realized through additional reinforcements and steel components (EN10025-2:2010 [10]), adopted to sustain both shear action and negative bending moments.

In the current scientific literature [11], several experimental tests were performed on different typologies of beam-to-column connections with CTSC beams and ordinary RC columns. Comparisons were made between traditional RC beam-to-column joints and different typologies of connections using CTSX beams; results highlighted comparable levels of strength and ductility and, in general, no relevant differences. Otherwise, difficulties still exist related to how to realize connections, or which design and detailing rules to adopt; it is quite usual that each single producer of CTSC system employs its own approach to realize connections between beams and vertical supports provided by adequate ductility levels and that, frequently, despite the structural typology, to all effects, a composite steel-concrete system reference for detailing joints is made to $\mathrm{RC}$ ones, since the satisfaction of consolidated design criteria is easier and more reliable.

2.2. Materials Used and Related Issues. The structural performance-under both monotonic and cyclic loading conditions-of structures, sub-structures, or single components with RC or composite steel-concrete structures is strongly affected by the mechanical properties of the materials adopted for their realization. In case of structures realized by adopting the CTSC technology, in particular, the behaviour is influenced not only by the characteristics of both concrete and steel adopted for the reinforcement but also by the way connections among the different steel components of the truss are realized. Particular attention shall be paid to the execution of welding used in the steel truss that is industrially realized, focusing on the welding between the diagonal reinforcements of the steel truss and the formwork plate and, besides, between the longitudinal and diagonal reinforcements of the truss.

During the last years, the interest arises concerning the possibility of using-for the steel truss-ordinary reinforcing steel bars, since no specific standards exist for the design and realization of CTSC elements, being therefore in the limbo between composite steel/concrete and RC components. Besides, the possibility of using reinforced steel instead of a structural one would represent a strong step forward in terms of economic effort, due to the well-known convenience of reinforcing steel with respect to traditional structural steel. Other problems are related to such assumption, mainly dependent on the different performance and characteristics between reinforcing steels (like, for example, B450 C or B500 B) and structural steels (grades like S235, S275, or higher), especially in the presence of welding. In the case of CTSC beams, as said, welding is used to connect the element of the internal steel truss, between the bottom plate constituting the formwork and the diagonal elements, and between the truss' components themselves. 
According to what is presented in the current scientific literature, it is well known that welding affects the resulting performance of the base material mainly in correspondence of the Heat Affected Zone (HAZ), due to the high temperature generated during the welding process; normally, with the acronym "HAZ," the area of base material not melted but whose microstructure and properties are altered by welding or heat-intensive cutting operations is identified. The effects of the high temperature during welding vary in relation to the steel grade adopted; usually, high-strength steels are affected by a relevant decrease of strength and ductility in the area close to HAZ, and the deterioration of the mechanical performance increases with the increase of base material resistance. Manik et al. [12] performed a wide experimental test campaign aiming to assess the influence of welding on the mechanical performance of mild steel and cast iron. Tensile tests highlighted that the stress and the deformation capacity of both mild steel and cast-iron specimens decreased after welding for any tested cross section, observing in the meanwhile the increase of the hardness value: this means, generally, that welding strongly affects the mechanical performance of the steel material.

Some problems may also arise while welding is applied to reinforcing steels like $\mathrm{B} 450 \mathrm{C}$ provided by the typical TempCore ${ }^{\circledR}$ microstructure. TempCore ${ }^{\circledR}$ steel is achieved by applying the two following phases of quenching and tempering, providing a microstructure where a ductile ferrite core is surrounded by an external martensite layer ensuring good strength. Being TempCore ${ }^{\circledR}$ originated from a thermomechanical treatment, the effects of welding on mechanical performance are evident especially in correspondence of the external hard martensitic layer. Nikolau and Papadimitriou [13] investigated the effects of welding on rebars used for retrofit intervention, mainly considering two different diffused grades like B400 (hotrolled) and B500 (TempCore $\left.{ }^{\circledR}\right)$, highlighting the influence of preheating on the resulting mechanical performance of the HAZ and the decrease of strength and deformation capacity. Similar results were found by Moustafa et al. [14], who analysed the behaviour of welded hot-rolled and TempCore ${ }^{\circledR}$ rebars, highlighting the influence of parameters like lap weld length, preheating, butt-weld side, and others on the decrease of ductility and yielding strength of TempCore ${ }^{\circledR}$, highlighting, respectively, reduction around the $50 \%$ and the $4 \%$. Similar tests were performed by Issa and Nasr [15] with the aim of evaluating the reliability of welded splices on rebars of different diameters, including techno-economic considerations for the final assessment. Apostolopoulos et al. [16] analysed the impact of corrosion on the mechanical properties of welded splices of reinforcing Steel S400 and B500 C through experimental tests also including corrosion, globally highlighting relevant ductility reduction. Corrosion and lap welding of reinforcing steel are the main reasons for the degradation of the mechanical performance, the behaviour of which varies according to the material, the location of failure, and the maximum elongation. Riva and Franchi [17] performed monotonic and low-cycle fatigue tests on butt-welded and cruciform welded joints realized with rebars of different diameters (varying between $8 \mathrm{~mm}$ and $24 \mathrm{~mm}$ ), highlighting, normally, a strong decrease of the ductility of the specimens with respect to the unwelded condition, resulting in a lower cyclic dissipative capacity and in a rapid deterioration of the performance. Lourenço [18], in his work, highlighted the influence of welding effects on TempCore ${ }^{\circledR}$ rebars, suffering more from welding (and corrosion) than cold worked or multialloy high-resistance steel.

In the present work, a deep investigation of the consequences of welding operations in the different reinforcements components used for the CTSC systems was performed. Attention was paid to analyse the efficacy of the welding adopted to join the steel formwork, realized with a micro-alloyed steel ordinarily adopted for structural steel components, and the diagonal reinforcement used for the steel truss. Two different problems are present affecting weldability performance: in relation to the amount of the different chemical components (mainly C, $\mathrm{Si}, \mathrm{P}$, and $\mathrm{Cu}$ ) affecting the hot-crackability, relevant differences can be revealed between traditional steels for structural components and reinforcing grades like TempCore ${ }^{\circledR}$. This suggests that deeper investigations are required before adopting such a reinforcement for CTSC beams.

\section{Experimental Test Campaign}

3.1. Selection and Design of the Welded Specimens. With the main aim of evaluating the reliability of adopting different steel typologies for the realization of the steel truss of CTSC systems, including both structural and reinforcing steels, the mechanical performance of welding to join the different components was evaluated by adopting the different possible schemes realized in practical applications. The efficacy and the failure modality of different welded components were assessed through the execution of mechanical tensile tests, comparing the results achieved from different specimens' typologies. In particular, the variability of the material used for the realization of the specimens was considered, while the two most common configurations observed in CTSC beams were adopted. The two different groups of specimens can be summarized as follows.

(1) Lap joint with single welding (in the following identified with the tag Lap) realizing connection between two adjacent specimens with circular cross section. The welding length was sized in relation to the strength of the connected element. Specimens were realized using both micro-alloyed (grade S355J0) and TempCore ${ }^{\circledR}$ B450 C steel bars (Figure 2). In the case of structural steel bars, two different round smooth sections were used, with one representing "big" specimens and the other representing "small" ones: for smooth bars, S355J0 diameters equal to 16 and $32 \mathrm{~mm}$ were used, while for ribbed $\mathrm{B} 450 \mathrm{C}$ bars, diameters equal to 14 and $30 \mathrm{~mm}$ were adopted.

(2) Double-sided lap joints (in the following identified with the tag $D u b$ ) with double welding was used to connect a structural steel plate made up of microalloyed steel (S355J0) and a steel bars was used both 

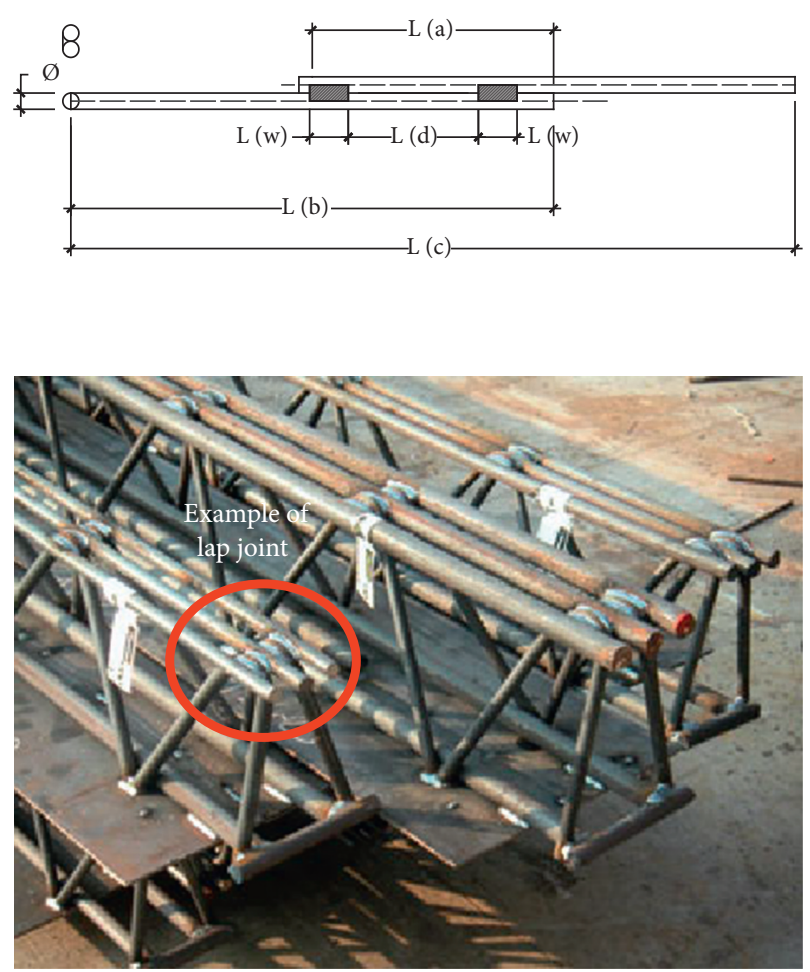

FIgURE 2: Lap Joint specimens.

with TempCore ${ }^{\circledR}$ B450 C steel and structural steel S355J0. The same diameters already adopted for Lap joints were used, while for the plate, representing the steel framework normally adopted in CTSC beams, a thickness always equal to $10 \mathrm{~mm}$ was employed (Figure 3).

In Figure $3 L_{w}$ represents the welding length and $L_{a}$ is the superposition length between the bars or between the plate and the bars.

For welding between steel reinforcing bars, prescriptions provided by EN17760-1:2007 [16] were adopted; both in the case of Lap and Dub joints, the minimum welding length needs to be equal to 4 times the diameter of the connected component; no specific indications are otherwise provided for structural steels, required only to follow EN1090:2012 [7]. The effective welding length of the specimens was designed based on design rules normally adopted for CTSC beams with the aim of representing what is realized in the common practice.

The following equations were adopted to determine the strength associated to welding:

$$
\begin{aligned}
F_{y d} & =\left(\frac{\pi \phi^{2}}{4}\right) \frac{f_{y d}}{\gamma_{M}}, \\
F_{u d} & =\left(\frac{\pi \phi^{2}}{4}\right) \frac{f_{u d}}{\gamma_{M}}, \\
f_{y w d} & =\frac{f_{\mathrm{MA}}}{\sqrt{3} \cdot \beta_{w} \cdot \gamma_{M 2}} .
\end{aligned}
$$
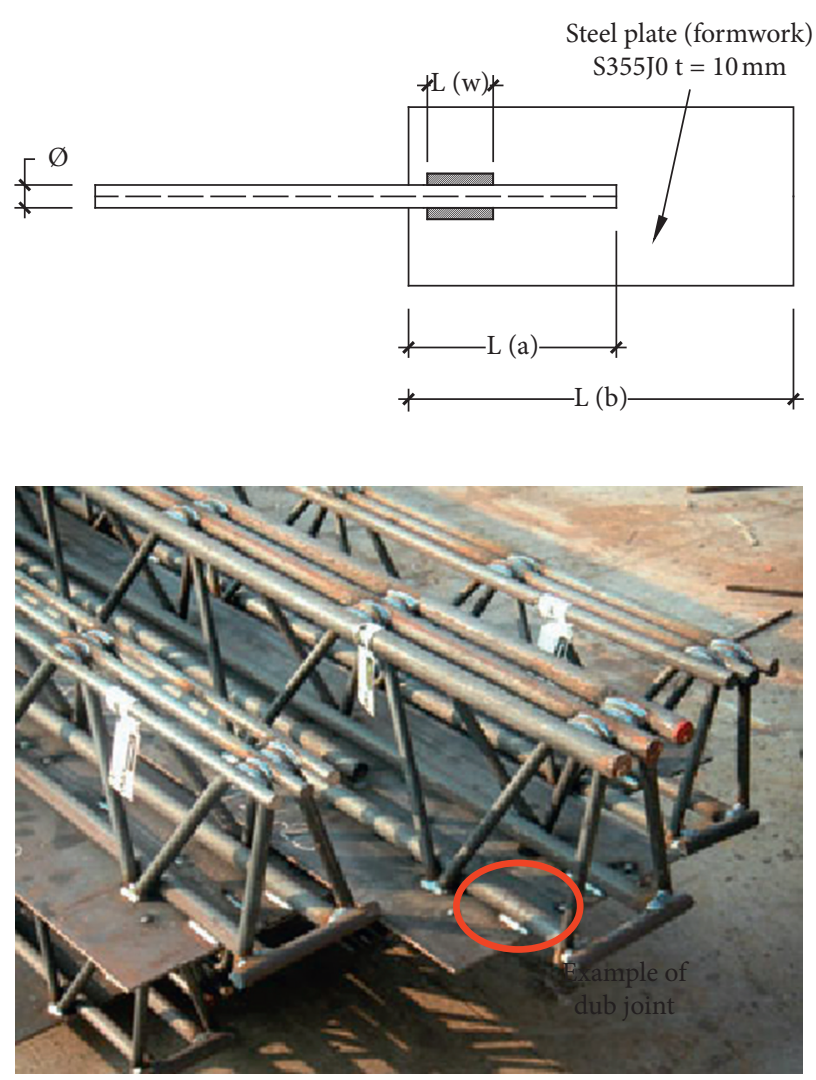

Figure 3: Double-sided lap joint between the steel plate and the rebar.

$F_{y d}$ and $F_{u d}$, respectively, being the design yielding and ultimate resistance of the component of diameter $\phi$, dependent on its geometry and on the material adopted; $f_{y d w}$ is, on the other hand, the welding yielding strength depending on the weld material, characterized by strength ( $f_{\mathrm{MA}}$ ) equal to $460 \mathrm{MPa}$, adopted through the $\beta_{w}$ and the $\gamma_{M 2}$ coefficients. The resulting design values for the two welded joint typologies are summarized in Table 1.

3.2. Mechanical Performance of the Base Material. Before characterizing the welding joints, tensile tests were performed on unwelded specimens (ribbed bars B450 C TempCore ${ }^{\circledR}$ and smooth bars S355J0) with the aim of assessing the mechanical performance of the base material allowing for the further comparative evaluation of welding effects on the samples. Tensile tests were performed on adequate length specimens following EN15630-1:2019 [19] prescriptions together with EN6892-1:2016 [20]. Table 2 shows the values achieved from the tensile tests performed on samples in terms of yielding and ultimate strength and deformation capacity.

3.3. Experimental Test on Lap Joints. Experimental tests on Lap joints were performed using a $1000 \mathrm{kN}$ force-control tensile machine. The dimensions of the specimens, in the case of small diameters (14 $\mathrm{mm}$ and $16 \mathrm{~mm}$, respectively, for B450 C and S355J0 steel), allowed for the introduction of 
TABle 1: Design characteristics of welded joints.

\begin{tabular}{|c|c|c|c|c|c|c|c|c|}
\hline \multirow[b]{2}{*}{$\begin{array}{l}\text { Steel material } \\
\text { Joint ID }\end{array}$} & \multicolumn{4}{|c|}{ Lap joints (lap) } & \multicolumn{4}{|c|}{ Double-sided joints (Dub) } \\
\hline & $\begin{array}{l}\text { S355J0 } \\
\text { Lap1 } \\
\end{array}$ & $\begin{array}{l}\text { S355J0 } \\
\text { Lap2 }\end{array}$ & $\begin{array}{c}\text { B450 C } \\
\text { Lap3 }\end{array}$ & $\begin{array}{c}\text { B450 C } \\
\text { Lap4 }\end{array}$ & $\begin{array}{l}\text { S355J0 } \\
\text { Dub1 }\end{array}$ & $\begin{array}{l}\text { S355J0 } \\
\text { Dub2 }\end{array}$ & $\begin{array}{c}\text { B450 C } \\
\text { Dub3 }\end{array}$ & $\begin{array}{c}\text { B450 C } \\
\text { Dub4 }\end{array}$ \\
\hline$\gamma_{M}$ & 1.05 & 1.05 & 1.15 & 1.15 & 1.05 & 1.05 & 1.15 & 1.15 \\
\hline$\phi(\mathrm{mm})$ & 16 & 32 & 14 & 30 & 16 & 32 & 14 & 30 \\
\hline \multirow{2}{*}{ Weld material $\mathrm{f}_{\mathrm{MA}}(\mathrm{MPa})$} & G46 & G46 & G46 & G46 & G46 & G46 & G46 & G46 \\
\hline & 460 & 460 & 460 & 460 & 460 & 460 & 460 & 460 \\
\hline$\beta_{\mathrm{w}}$ & 0.90 & 0.90 & 0.90 & 0.90 & 0.9 & 0.9 & 0.9 & 0.9 \\
\hline$\gamma_{\mathrm{M} 2}$ & 1.35 & 1.35 & 1.35 & 1.35 & 1.35 & 1.35 & 1.35 & 1.35 \\
\hline $\mathrm{F}_{\mathrm{yd}}(\mathrm{kN})$ & 67.9 & 271.8 & 60.2 & 276.5 & 67.9 & 271.8 & 60.2 & 2765 \\
\hline $\mathrm{F}_{\mathrm{ud}}(\mathrm{kN})$ & 97.6 & 390.4 & 72.3 & 331.8 & 97.6 & 390.4 & 72.3 & 331.8 \\
\hline $\mathrm{F}_{\mathrm{ydw}}(\mathrm{MPa})$ & 218.6 & 218.6 & 218.6 & 218.6 & 218.6 & 218.6 & 218.6 & 218.6 \\
\hline$L_{\mathrm{w}}(\mathrm{mm})$ & 46.5 & 93.0 & 39.3 & 84.3 & 65.8 & 131.6 & 55.6 & 119.2 \\
\hline$L_{\mathrm{w}, \min }($ ISO $17660-1)$ & - & - & 56 & 120 & - & - & 56 & 120 \\
\hline
\end{tabular}

TABLE 2: Results of tensile tests on the bars.

\begin{tabular}{lccccc}
\hline Steel material & $\phi_{\mathrm{n}}(\mathrm{mm})$ & Used for specimens & $R_{\mathrm{e}}(\mathrm{MPa})$ & $R_{\mathrm{m}}(\mathrm{MPa})$ & $\mathrm{A}_{\mathrm{gt}}(\%)$ \\
\hline S355J0 & 16 & Lap1, Dub1 & 365.0 & 533.7 & 16.4 \\
B450 C & 14 & Lap3, Dub3 & 492.0 & 603.2 & 12.0 \\
S355J0 & 32 & Lap2, Dub2 & 356.1 & 517.0 & 23.1 \\
B450 C & 30 & Lap4, Dub4 & 593.8 & 738.1 & 29.3 \\
\hline
\end{tabular}

displacement transducers to measure deformations. The effective lengths of the two welds used to join the two specimens $\left(L_{w 1}, L_{w 2}\right)$, measured on produced specimens, are reported in Table 3, with $L_{a}$ being the whole superposition length. For each Lap joint specimens' typology, in relation to the diameter and material, four tensile tests were performed to assess the welding resistance and the failure modality of the joint.

The results of experimental tests are presented in Table 3 in terms of ultimate load and failure modality, with specific reference to the Heat Affected Zone (HAZ). As visible, in case of Lap1 joints (S355J0, ? $16 \mathrm{~mm}$ ), collapse was achieved for an average strength of about $520 \mathrm{MPa}$, approximately equal to the tensile strength achieved from tensile tests on unwelded specimens. In samples characterized by small diameter, failure happened outside the HAZ and interested therefore the rebars, according to what assumed in the design (Figure 4). Similar considerations can also be made in the case of Lap3 joints (B450 C, $\phi 14 \mathrm{~mm}$ ), characterized by an average ultimate strength equal to about $613 \mathrm{MPa}$, approximately equal to the ultimate strength achieved from tensile tests on single bars.

Similar considerations can be made even for large-diameter lap joints realized with structural steel. The only exception is for one of the Lap2 specimens evidencing a premature failure in correspondence of the welding, probably not perfectly realized. The failure happened in correspondence of the bar for load/strength values approximately in the range of the material ultimate tensile stress, highlighting the efficacy of welding and, at the same time, no relevant effects in correspondence of the HAZ. A globally ductile collapse modality was observed: this is confirmed by the necking appreciated in correspondence of the tested samples.
On the other hand, as visible from Figure 5, in the case of large-diameter TempCore ${ }^{\circledR}$ specimens, failure usually took place very close to the HAZ, evidencing, at the microscopic level, a more brittle collapse modality, confirmed by the lack of visible necking normally characterizing steel reinforcements. This means, simply, that welding effects on TempCore ${ }^{\circledR}$ steel, when a larger thickness is involved, -are relevant and strongly influence the overall structural performance. Figure 6(a) summarizes the results achieved in terms of ultimate load at failure for the different Lap joints.

3.4. Experimental Test on Double Sided Joints. Experimental tensile tests on Dub joints were performed using, once again, a $1000 \mathrm{kN}$ force-control tensile machine; with the aim of correctly executing the tests, some modifications on the as-received large-diameter samples were executed (Dub2 and Dub4) (Figure 7). For each Dub-joint specimens' typology (in relation to material and diameter), five tests were performed.

Results are presented in Table 4 in terms of load and stress values in correspondence of failure and percentage necking. This last parameter is representative of the ductility and deformation capacity of the sample; it is evaluated as $Z=\left(A_{0}-A_{\text {fin }} / A_{0}\right)$ (being $\mathrm{A} 0$ and Afin, respectively, the area of the cross section before and after failure in correspondence of the fracture surface). Considerations similar to the ones already performed on Lap joints can be performed: in the case of micro-alloyed steels (S355J0), even in the presence of large rebar diameter (Figures 8 and 9), a ductile failure mechanism was observed, with collapse taking place always outside the Heat Affected Zone; in the case of reinforcing steel $\mathrm{B} 450 \mathrm{C}$, differences were encountered in relation to the diameter, since in the case of large ones failure 
TABLE 3: Summary of tests' results on Lap joints.

\begin{tabular}{|c|c|c|c|c|c|c|c|c|c|}
\hline \multicolumn{2}{|c|}{ Spec. Id } & \multirow{2}{*}{$\begin{array}{c}\text { Steel } \\
\text { S355J0 }\end{array}$} & \multirow{2}{*}{$\frac{\phi(\mathrm{mm})}{16}$} & \multirow{2}{*}{$\frac{L_{\mathrm{a}}(\mathrm{mm})}{158}$} & \multirow{2}{*}{$\frac{L_{\mathrm{w} 1}(\mathrm{~mm})}{55}$} & \multirow{2}{*}{$\frac{L_{\mathrm{w} 2}(\mathrm{~mm})}{58}$} & \multirow{2}{*}{$\begin{array}{c}\mathrm{Fu}(\mathrm{kN}) \\
104,0\end{array}$} & \multirow{2}{*}{$\frac{f_{\mathrm{u}}(\mathrm{MPa})}{517,0}$} & \multirow{2}{*}{$\begin{array}{c}\text { Failure modality/position } \\
\text { Failure of the rebar, outside HAZ }\end{array}$} \\
\hline Lap1 & 1 & & & & & & & & \\
\hline Lap1 & 2 & S355J0 & 16 & 160 & 56 & 58 & 104,0 & 517,0 & Failure of the rebar, outside HAZ \\
\hline Lap1 & 3 & S355J0 & 16 & 160 & 65 & 65 & 105,5 & 524,8 & Failure of the rebar, outside HAZ \\
\hline Lap1 & 4 & S355J0 & 16 & 160 & 60 & 62 & 104,5 & 519,9 & Failure of the rebar, outside HAZ \\
\hline Lap3 & 1 & B450 C & 14 & 142 & 58 & 60 & 94,5 & 614,1 & Failure close to the HAZ \\
\hline Lap3 & 2 & B450 C & 14 & 145 & 60 & 60 & 96,5 & 626,9 & Failure close to the HAZ \\
\hline Lap3 & 3 & B450 C & 14 & 140 & 58 & 58 & 91,8 & 596,3 & Failure close to the HAZ \\
\hline Lap3 & 4 & B450 C & 14 & 143 & 58 & 59 & 94,5 & 614,1 & Failure close to the HAZ \\
\hline Lap2 & 1 & S355J0 & 32 & 320 & 120 & 120 & 431,5 & 536,5 & Welding failure \\
\hline Lap2 & 2 & S355J0 & 32 & 320 & 120 & 120 & 433,5 & 539,0 & Failure of the rebar, outside HAZ \\
\hline Lap2 & 3 & S355J0 & 32 & 320 & 120 & 120 & 408,0 & 507,3 & Failure of the rebar, outside HAZ \\
\hline Lap2 & 4 & S355J0 & 32 & 319 & 122 & 122 & 437,4 & 543,8 & Failure of the rebar, outside HAZ \\
\hline Lap4 & 1 & B450 C & 30 & 302 & 120 & 125 & 540,3 & 764,4 & Failure of the rebar, outside HAZ \\
\hline Lap4 & 2 & B450 C & 30 & 303 & 122 & 125 & 515,8 & 729,8 & Failure close to the HAZ \\
\hline Lap4 & 3 & B450 C & 30 & 302 & 120 & 123 & 523,7 & 740,9 & Failure close to the HAZ \\
\hline Lap4 & 4 & B450 C & 30 & 302 & 120 & 125 & 549,2 & 776,9 & Failure close to the HAZ \\
\hline
\end{tabular}

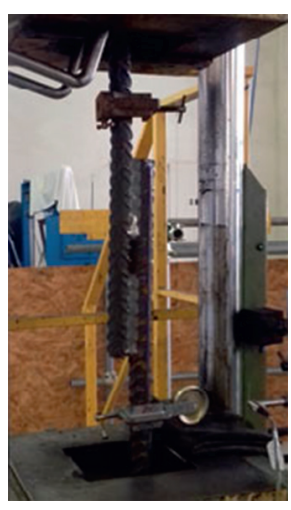

(a)

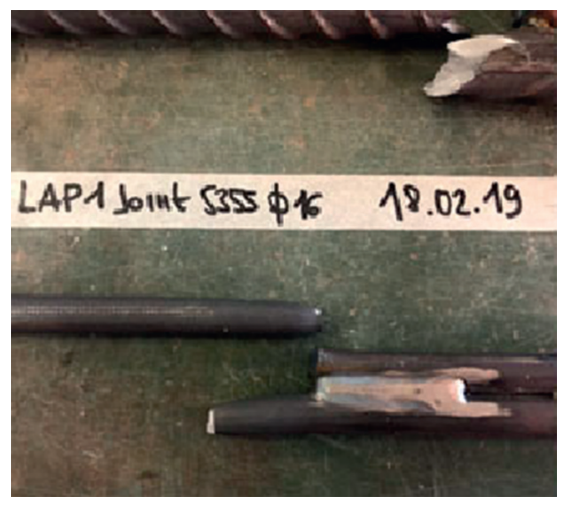

(b)

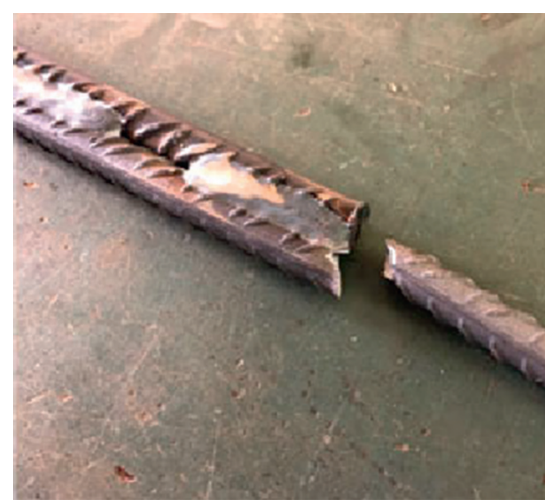

(c)

Figure 4: Experimental tests on lap joints (a); example of failure in smooth (b) and ribbed (c) samples of small diameter. In case of ribbed bars (c), the brittle failure close to the HAZ is evident.

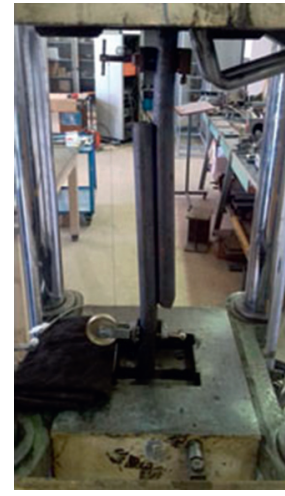

(a)

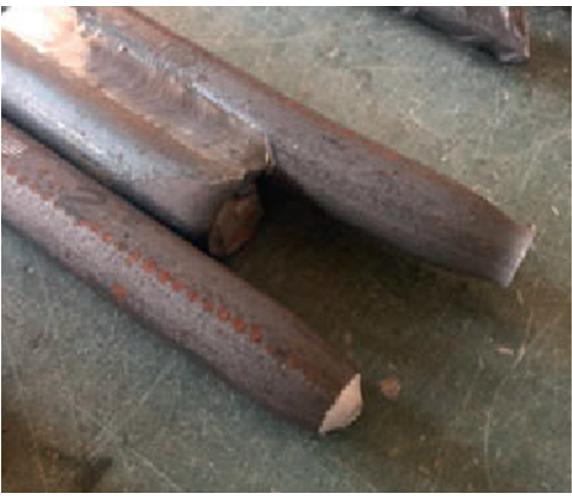

(b)

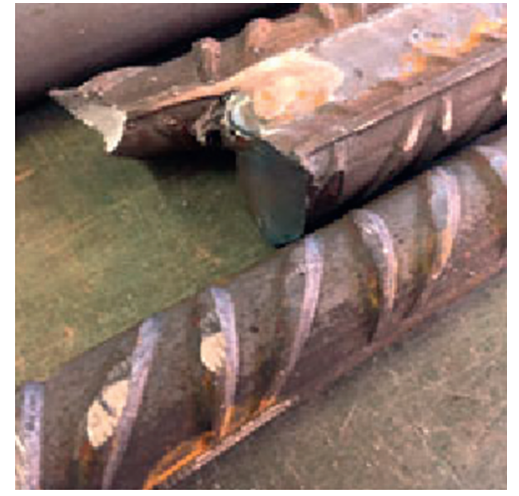

(c)

FIgURe 5: Experimental tests on lap joints (a) and example of failure in smooth (b) and ribbed bars (c) of large diameter. In case of ribbed bars, the lack of necking and the failure close to the HAZ is evident. 


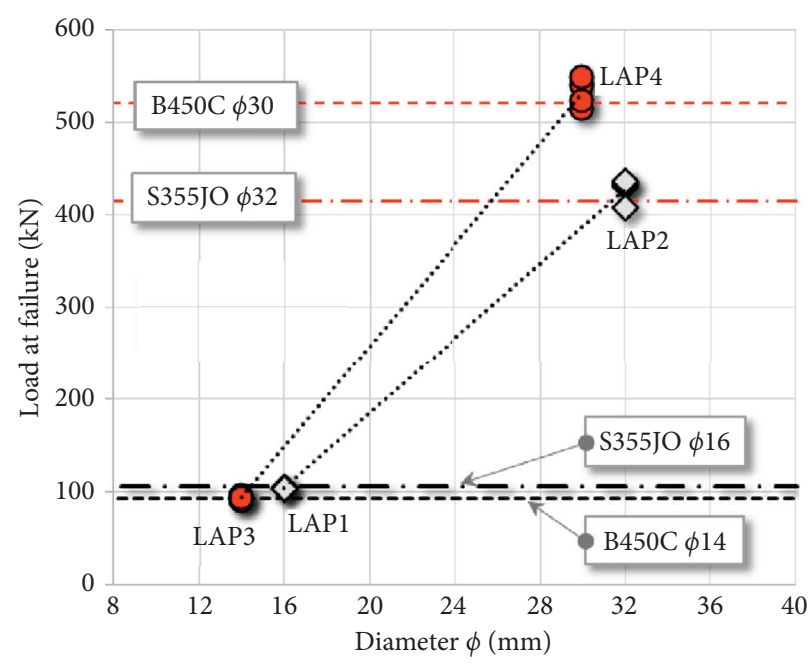

$\diamond \mathrm{S} 355 \mathrm{JO}$

B $450 \mathrm{C}$

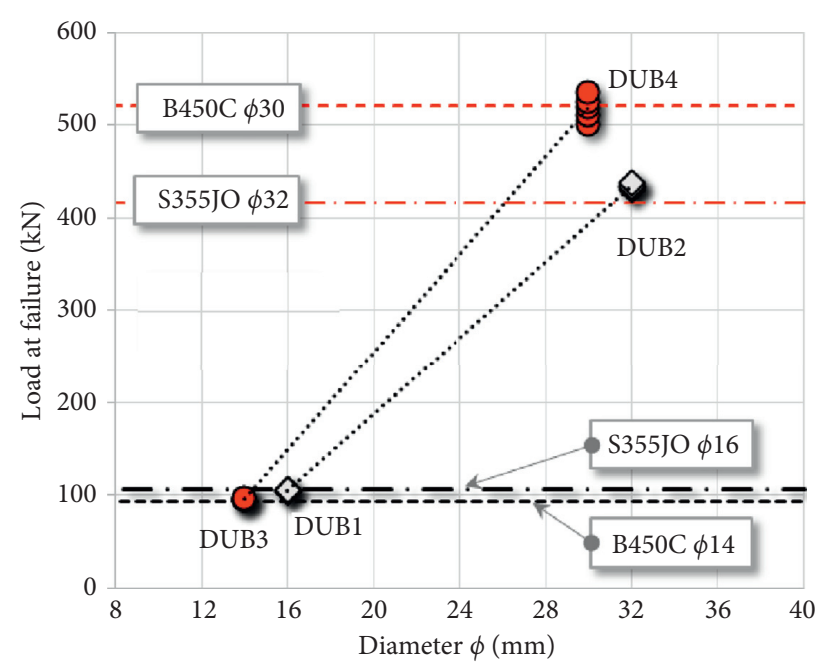

$\diamond \mathrm{S} 355 \mathrm{JO}$

B450C

(a)

(b)

FIGURE 6: Results of experimental tests in terms of load corresponding to failure for the different specimens and comparison with reference data for micro-alloyed and ribbed bars for (a) lap joints and (b) dub joints.

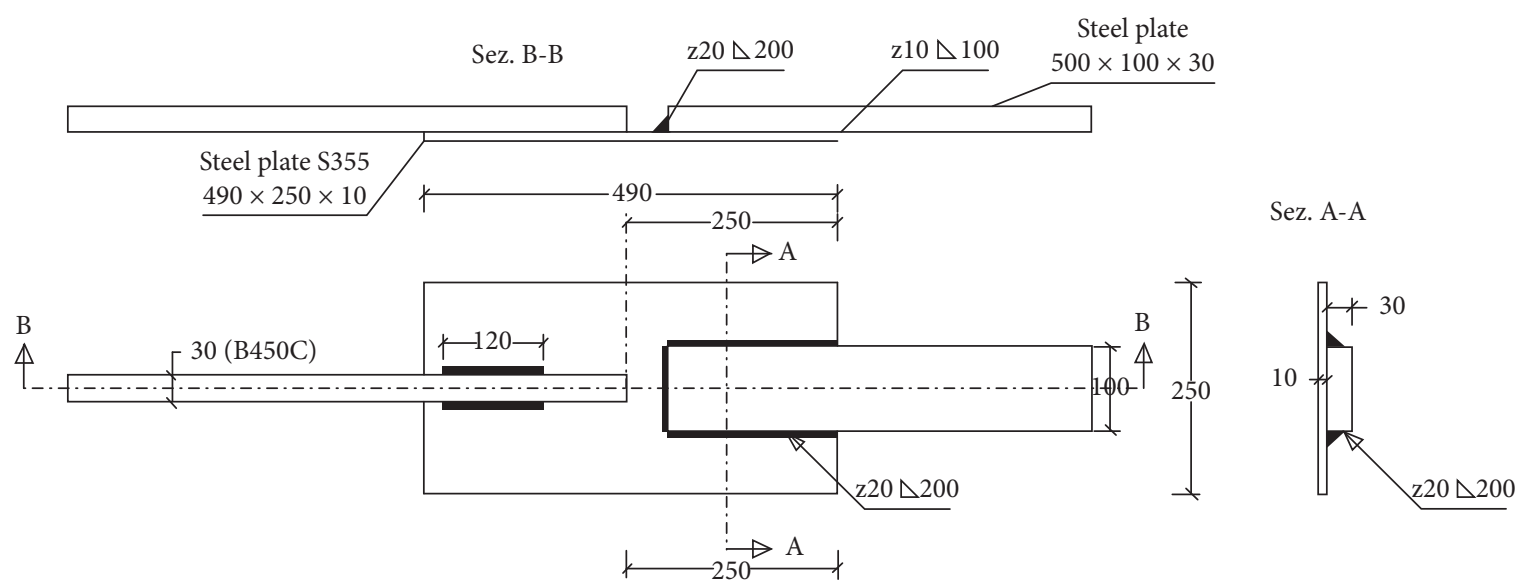

Figure 7: Modification of large-diameter Dub-joint specimens for placing in the experimental test machine.

happens in the proximity of the area interested by the welding effect, leading to brittle failures also highlighted by very low value of necking (Table 4). Figure 6(b) summarizes the results achieved in terms of the ultimate load at failure for the different Dub joints.

3.5. Metallographic and Fractographic Investigations. Several tested specimens were subjected to metallographic and fractographic investigations; analyses involved both the base material (reinforcing TempCore ${ }^{\circledR}$ and structural microalloyed steels) and welding in correspondence of the Heat Affected Zone (HAZ). Hardness tests were executed.

Investigations were aimed to define the original $\mathrm{mi}-$ crostructure typical of the material and the modifications induced by the welding process. Specific analysis of the fracture surface after the execution of tensile tests using SEM allowed to draw some considerations concerning the relationship among the failure modality, welding consequences/effects, and the mechanical behaviour highlighted by tensile tests as already presented.

3.5.1. Metallographic and Hardness Tests. SEM investigations were performed on opportunely treated specimens with and without chemical attack, realized through immersion for several seconds in Nital 2\%, with the aim of highlighting the metallographic structure at different magnifications. Hardness tests were executed using HV 10 load. Results are presented in Figure 10, where the typical TempCore ${ }^{\circledR}$ microstructure and the micro-alloyed one are well visible in their main differences: $\mathrm{B} 450 \mathrm{C}$ reinforcing steel evidenced the characteristic ferritic-pearlitic microstructure of the internal ductile core, while for S355J0 the typical fine-grain microstructure was appreciated. 
Table 4: Summary of tests' results on Dub joints.

\begin{tabular}{|c|c|c|c|c|c|c|c|c|c|c|}
\hline Spec. Id & & Material & $\phi(\mathrm{mm})$ & $\mathrm{La}(\mathrm{mm})$ & $L_{\mathrm{w} 1}(\mathrm{~mm})$ & $L_{\mathrm{w} 2}(\mathrm{~mm})$ & $\mathrm{Fu}(\mathrm{kN})$ & $f_{\mathrm{u}}(\mathrm{MPa})$ & $\mathrm{Z}(\%)$ & Failure modality/position \\
\hline Dub1 & 1 & S355J0 & 16 & 111,3 & 60,0 & 59,7 & 105,5 & 524,8 & 57 & Bar failure, outside HAZ \\
\hline Dub1 & 2 & S355J0 & 16 & 111,6 & 58,3 & 61,1 & 105,5 & 524,8 & 64 & Bar failure, outside HAZ \\
\hline Dub1 & 3 & S355J0 & 16 & 108,9 & 59,1 & 59,0 & 104,3 & 519,0 & 63 & Bar failure, outside HAZ \\
\hline Dub1 & 4 & S355J0 & 16 & 111,2 & 57,0 & 57,0 & 104,3 & 519,0 & 45 & Bar failure, outside HAZ \\
\hline Dub1 & 5 & S355J0 & 16 & 111,2 & 57,0 & 53,0 & 105,5 & 524,8 & 51 & Bar failure, outside HAZ \\
\hline Dub3 & 1 & B450 C & 14 & 111,3 & 56,8 & 55,7 & 95,3 & 619,2 & 18 & Bar failure, outside HAZ \\
\hline Dub3 & 2 & $\mathrm{~B} 450 \mathrm{C}$ & 14 & 111,6 & 59,4 & 54,4 & 96,5 & 626,9 & 11 & Bar failure, outside HAZ \\
\hline Dub3 & 3 & $\mathrm{~B} 450 \mathrm{C}$ & 14 & 115,0 & 53,4 & 56,3 & 95,7 & 621,8 & 30 & Bar failure, outside HAZ \\
\hline Dub3 & 4 & B $450 \mathrm{C}$ & 14 & 111,1 & 52,0 & 55,0 & 96,1 & 624,3 & 25 & Bar failure, outside HAZ \\
\hline Dub3 & 5 & $\mathrm{~B} 450 \mathrm{C}$ & 14 & 111,2 & 57,0 & 53,0 & 96,5 & 626,9 & 26 & Bar failure, outside HAZ \\
\hline Dub2 & 1 & S355J0 & 32 & 230,8 & 127,0 & 127,0 & 435,4 & 541,4 & 61 & Bar failure, outside HAZ \\
\hline Dub2 & 2 & S355J0 & 32 & 230,0 & 120,0 & 115,0 & 431,5 & 536,5 & 67 & Bar failure, outside HAZ \\
\hline Dub2 & 3 & S355J0 & 32 & 240,0 & 120,0 & 115,0 & 433,5 & 539,0 & 57 & Bar failure, outside HAZ \\
\hline Dub2 & 4 & S355J0 & 32 & 240,0 & 122,0 & 116,0 & 433,5 & 539,0 & 62 & Bar failure, outside HAZ \\
\hline Dub2 & 5 & S355J0 & 32 & 230,6 & 130,0 & 120,0 & 437,4 & 543,8 & 69 & Bar failure, outside HAZ \\
\hline$\overline{\text { Dub4 }}$ & 1 & B450 C & 30 & 230,5 & 120,0 & 125,0 & 502,1 & 710,3 & 9 & Close to the HAZ \\
\hline Dub4 & 2 & B450 C & 30 & 230,6 & 117,0 & 117,0 & 511,9 & 724,2 & 5 & Close to the HAZ \\
\hline Dub4 & 3 & B450 C & 30 & 230,0 & 120,0 & 120,0 & 519,8 & 735,3 & 30 & Bar failure, outside HAZ \\
\hline Dub4 & 4 & B450 C & 30 & 230,5 & 120,0 & 120,0 & 525,6 & 743,6 & 7 & Close to the HAZ \\
\hline Dub4 & 5 & $\mathrm{~B} 450 \mathrm{C}$ & 30 & 230,7 & 115,0 & 108,0 & 535,4 & 757,5 & 14 & Close to the HAZ \\
\hline
\end{tabular}

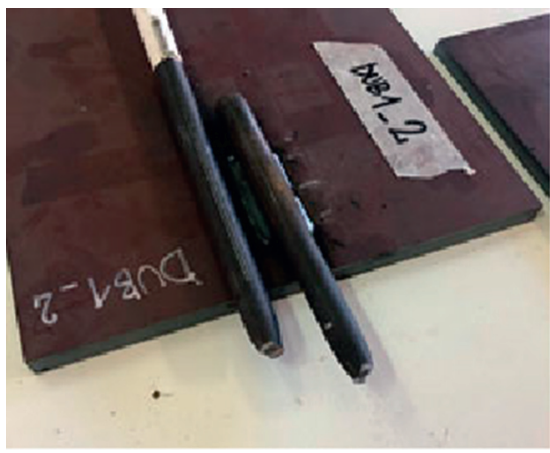

(a)

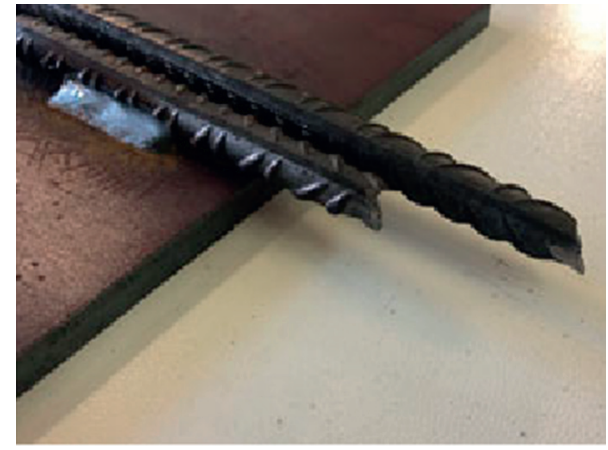

(b)

FIGURE 8: Failure of small-diameter Dub joints (smooth sample (a) and ribbed sample (b)). Failure always happens in correspondence of the rebar for values comparable to the ones achieved from tensile tests on the unwelded samples.

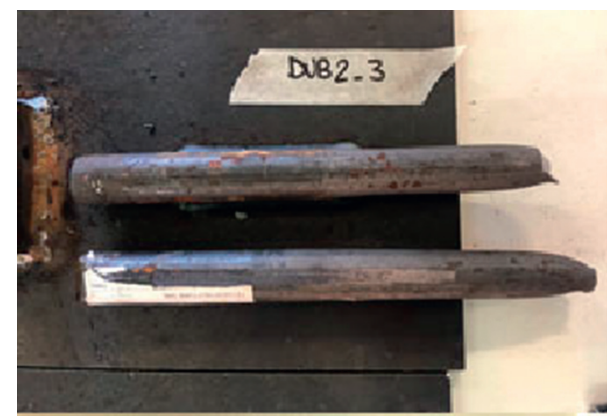

(a)

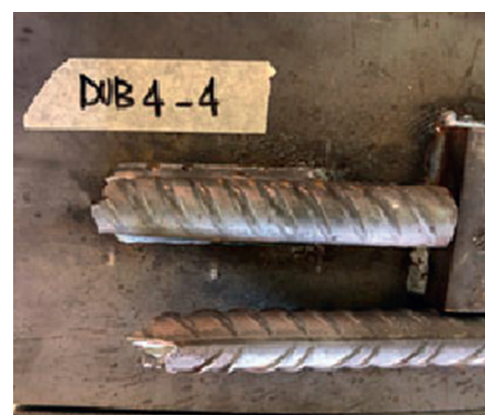

(b)

FiguRE 9: Failure in correspondence of large-diameter Dub joints. The difference between smooth and ribbed bar is evident: in structural steel necking is visible, highlighting the ductile behaviour, while in case of TempCore ${ }^{\circledR}$ the fracture happened in the HAZ.

The effects of welding in correspondence of the HAZ for the two considered steel typologies were evaluated. In particular, Figure 11 evidences the typical aspect of
TempCore ${ }^{\circledR}$ welding, characterized by the increase of the grain size in the HAZ and the existence of the characteristic "band structure.". TempCore ${ }^{\circledR}$ steels are normally more 


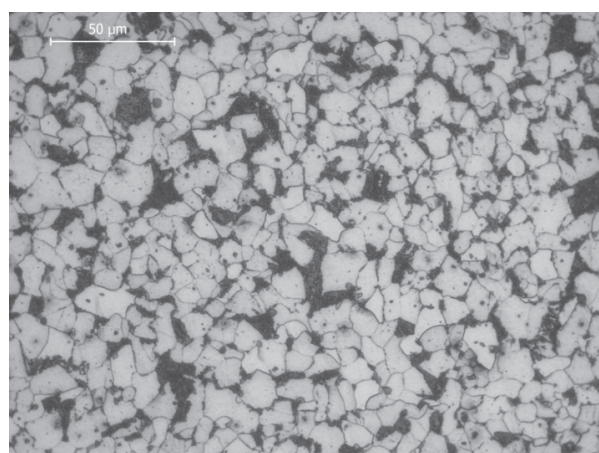

(a)

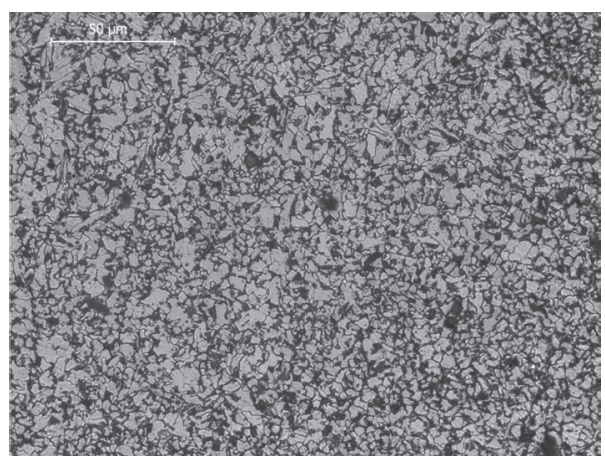

(b)

Figure 10: Typical microstructure of (a) TempCore ${ }^{\circledR}$ B450C steel and (b) micro-alloyed S355J0 steel.
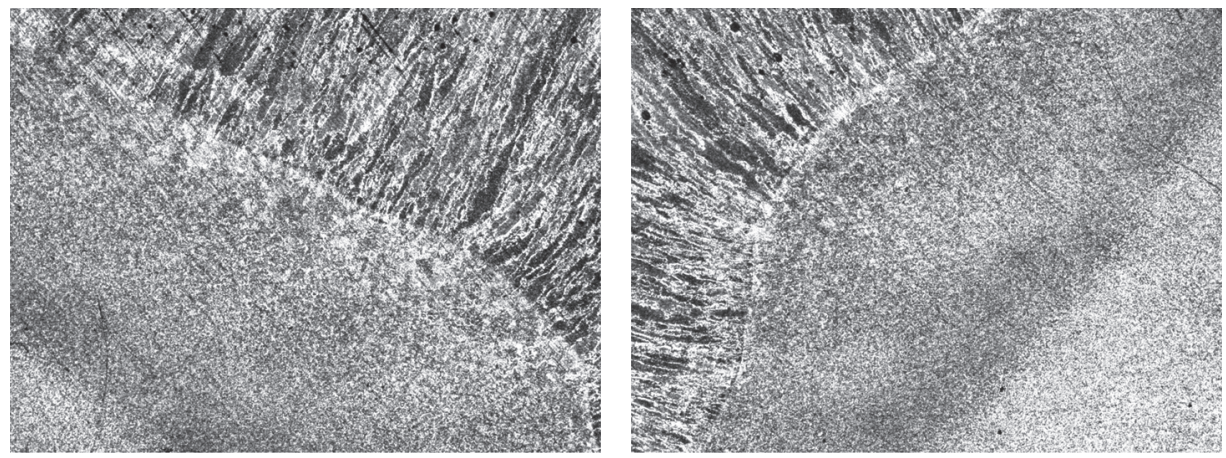

Figure 11: Details of the HAZ in TempCore ${ }^{\circledR}$ welding. Note the increase of the grain size in HAZ in correspondence of the external martensitic layer.
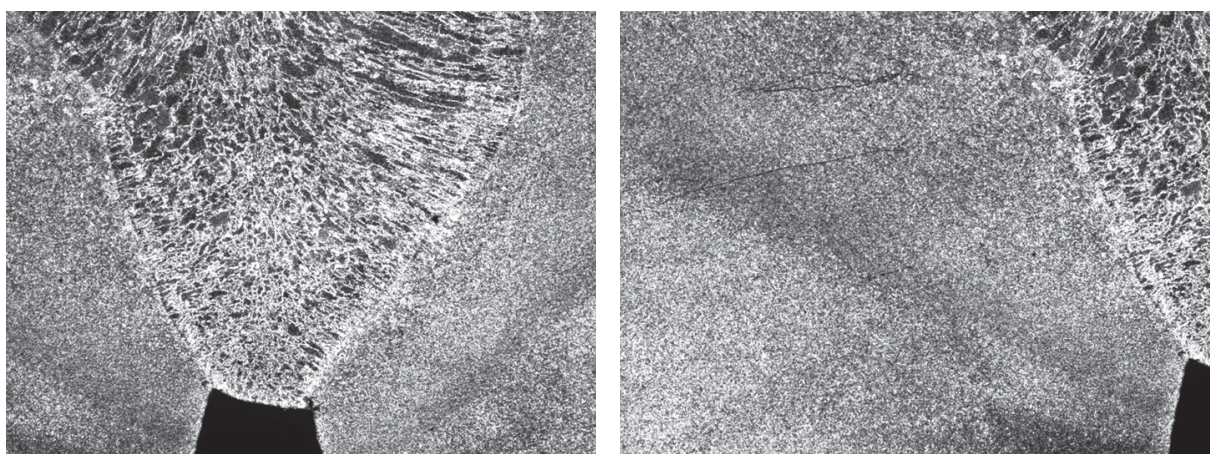

FIGURE 12: Welding in correspondence of micro-alloyed steel S355J0: the effects of HAZ are negligible; the typical band structure with following variations of grain size are visible.

hardenable with respect to micro-alloyed ones, and they normally lead to bainitic or even martensitic structures, with a resulting brittle behaviour. Different was, on the other hand, the behaviour of the HAZ in the case of welding on micro-alloyed steels, where, due to the chemical composition of the material itself, the HAZ was difficult to be recognized and the increase of the grain size and the development of brittle areas were practically absent (Figure 12).

Mechanical tests' results presented in the previous paragraph evidenced that TempCore ${ }^{\circledR}$ steel is characterized by a strong heterogeneity directly caused by the thermomechanical process adopted for their production and leading to the increase of the hardness value in correspondence of the external layer. The application of the quenching process and the following self-tempering due to the internal heat of the specimen are responsible for the resulting microstructure and mechanical performance. The results of hardness tests performed in correspondence of joints are presented in Table 5, where the average values of the three executed tests are presented. 
TABLE 5: Results of hardness tests (average values on three specimens).

\begin{tabular}{lcccc}
\hline Steel type & Material (core) & Material (external surface) & HAZ & Melting area \\
\hline TempCore ${ }^{\circledR}$ & $140 \mathrm{HV}$ & $230 \mathrm{HV}$ & $280 \mathrm{HV}$ & $198 \mathrm{HV}$ \\
HSLA & $180 \mathrm{HV}$ & $183 \mathrm{HV}$ & $201 \mathrm{HV}$ & $195 \mathrm{HV}$ \\
\hline
\end{tabular}

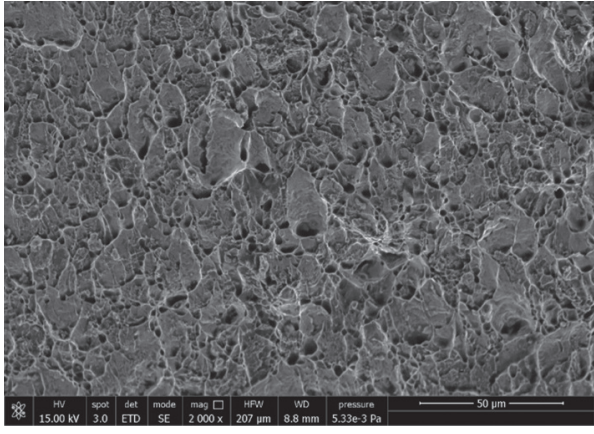

(a)

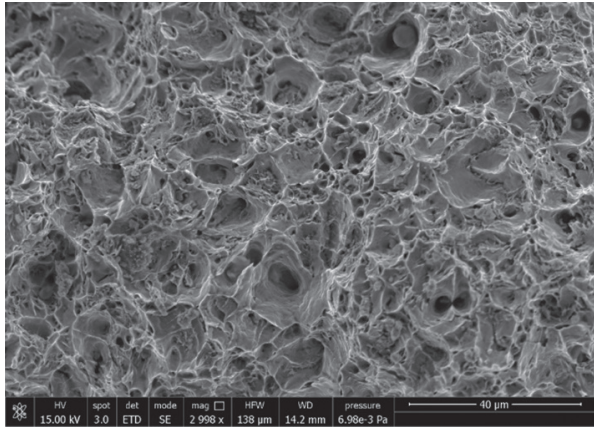

(b)

Figure 13: (a) TempCore ${ }^{\circledR}$ B450C steel: ductile microstructure; (b) S355J0 micro-alloyed rebar: ductile microstructure.

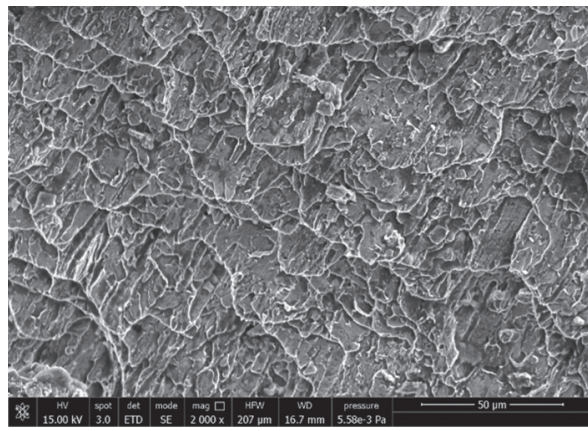

(a)

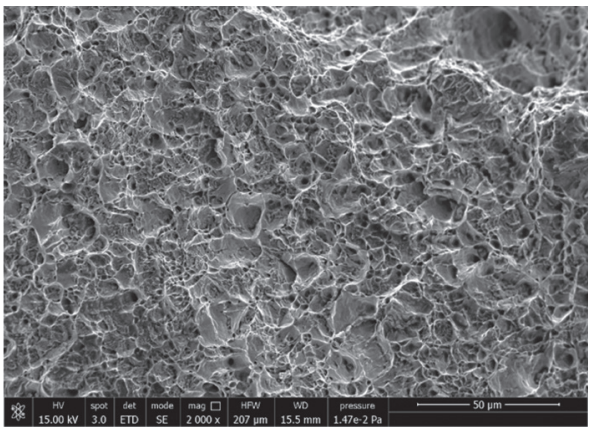

(b)

Figure 14: Fracture surface in correspondence of welding of (a) TempCore ${ }^{\circledR}$ rebar with brittle structure and (b) micro-alloyed steel with ductile structure.

According to Table 5, differences can be observed in correspondence of the core (characterized by the typical ferritic-pearlitic microstructure) with lower hardness values with respect to the external martensitic layer. On the other hand, S355J0 steel showed a fully homogeneous structure. The most interesting information, otherwise, is related to the HAZ: if welding is applied to TempCore ${ }^{\circledR}$, in the HAZ, dangerous hardness concentrations (in the specific case with values up to $280 \mathrm{HV}$ ) appeared, due to the tendency of the material to achieve hard and brittle structures due to the cooling following the welding process.

3.5.2. Fractographical Investigations with SEM. The fracture surface of several samples subjected to mechanical tests was observed with the aim of analysing the failure modality. After specific preparation, samples were observed through SEM (type FEI Quanta 450 ESEM FEG), and results are presented in the following pictures. According to Figure 13, it can be assessed that the unwelded steel material, on its own, was characterized by a ductile behaviour, both in the case of micro-alloyed S355J0 steel and of TempCore ${ }^{\circledR}$ B450 C reinforcing grade.

The origin of brittle fracture surfaces was then the direct consequence of the application of the welding process. In the case of TempCore ${ }^{\circledR}$ reinforcing steel, the dramatic brittle aspect of the fracture surface was able to confirm the results of the mechanical tests (Figure 14(b)), while, at the same time, in the case of S355J0 the HAZ was characterized by a ductile behaviour assessing the maintenance of the ductility without unexpected collapse modalities even after weld execution (Figure 14(a)).

\section{Conclusions}

In the present paper, one of the main issues affecting structures realized using the CTSC system (for example, NPS ${ }^{\circledR}$ systems in their different possible configurations), 
concerning effects of welding on the steel components constituting the internal truss, was taken into account after strictly characterizing the reliability of the resulting system and the resulting structural performance mainly in terms of ductility and deformation capacity. The problem was analysed from an experimental point of view by comparing the performance of two steel typologies adopted for the realization of the steel truss: one structural micro-alloyed steel grade (S355J0) and one reinforcing steel (B450 C) achieved through the application of the thermomechanical TempCore ${ }^{\circledR}$ process. According to standards for composite steel-concrete structures (D.M.17/01/2018; EN1998-1:2005), the adoption of structural steel is mandatory for the realization of steel components; on the other hand, the CTSC structural typology of constructions lies between composite steel-concrete and RC ones, which is frequently compared in terms of joints' realization with the aim of being used for seismic areas. The systems lie in the middle between composite and RC constructions, and some questions arise in the last years about the possibility of adopting reinforcing steels for the realization of the internal steel truss connected to the bottom steel plate. In this sense, the evaluation of welding effects on the structural performance needs to be clarified.

Several mechanical, microstructural, and fractographic investigations were performed with the aim of determining main differences and the possible consequence on the structural performance of resulting buildings adopting such technological system and adopting structural or reinforcing steels. Trying to summarize the achievements of the developed research, some important conclusions can be drafted.

According to what was observed from experimental tests, it can be assessed that, from a technological point of view, reinforcing TempCore ${ }^{\circledR}$ steels or micro-alloyed ones, if opportunely sized to be used as rebar accounting for the different strength of the base material, almost own the same properties. But if the mechanical performance of a single unwelded component is similar both in terms of strength, ductility, and failure modality, relevant differences can be observed when welding is applied: the ductility of welded TempCore ${ }^{\circledR}$ specimens is affected by relevant drops leading to brittle failures, lack of plastic deformation, and brittle fracture surface in correspondence of the Heat Affected Zone (HAZ).

This issue, and the related structural consequences, is rooted not in the welding process but, on the contrary, strictly depends on the materials themselves: as known, TempCore ${ }^{\circledR}$ grades achieve their mechanical performance after the application of a thermomechanical process consisting of the following two phases of quenching and tempering, leading to a high sensitivity toward additional thermal cycles like the ones induced by welding. Microalloyed fine-grain steels like S355J0 (or similar) otherwise own their mechanical properties due to the configuration of the ferritic grain, with very reduced dimension, achieved from the optimal combination of chemical components and thermomechanical lamination techniques, being then not affected by the development of brittle phases when welding is applied.
The entity of brittle phenomena is dependent on a wide variety of factors, among them the dimension of the structural component where welding is applied and the parameters adopted during the process. Otherwise, as a general comment and in relation to the results that were achieved in the present work, widely described in the previous paragraphs, welding in the presence of TempCore ${ }^{\circledR}$ steel shall be avoided, especially in those cases where it is not possible to accurately check the effectiveness of realization, like usually happens in the case of ordinary civil or industrial constructions.

\section{Data Availability}

The data are fully presented in the manuscript.

\section{Conflicts of Interest}

The authors declare that they have no conflicts of interest.

\section{Acknowledgments}

The authors would like to thank Tecnostrutture S.r.l for the realization of the specimens used for the experimental tests; besides, special thanks are due to Michele Di Ruscio of the "Laboratorio Ufficiale per le Esperienze sui Materiali da Costruzione" of Pisa University for the important support given during the execution of the experimental mechanical test campaign and Randa Ishak for the relevant contribution provided for SEM and metallographic investigations. The present research received no specific grant from any funding agency in the public, commercial, or not-for-profit sectors.

\section{References}

[1] D. M. 17/01/2018 "Norme Tecniche per le Costruzioni", Ministero delle Infrastrutture e dei Trasporti.

[2] CEN-European Committee for Standardization, EN 1998-1: 2005, 2005 Eurocode 8: Design of Structures for Earthquake Resistance - Part 1: General Rules, Seismic Actions and Rules for Buildings, CEN-European Committee for Standardization, Brussels, Belgium, 2005.

[3] C. Amadio, L. Macorini, S. Sorgon, and G. Suraci, "Analisi di un sistema ibrido sismo-resistente costituito da elementi tralicciati in acciaio inglobati nel calcestruzzo," Congresso C.T.E.vol. 17, pp. 801-810, 2008.

[4] L. Tesser and R. Scotta, "Flexural and shear capacity of composite steel truss and concrete beams with inferior precast concrete base," Engineering Structures, vol. 49, pp. 135-145, 2013.

[5] E. Brunesi, D. Bellotti, D. Bolognini, and R. Nascimbene, Sviluppo di modelli per la definizione della rigidezza equivalente di differenti configurazioni di travi tralicciate, XIV Convegno di Ingegneria Sismica - ANIDIS, Bari, Italy, 2011.

[6] R. Scotta and L. Tesser, "Indagine sperimentale su nodi travepilastro innovativi per telai sismo-resistenti," Le prospettive di sviluppo delle opere in c.a. nel terzo millennio, Atti convegno AICAP, Padua, Italy, 2011.

[7] EN 1090-1, "Execution of steel structures and aluminium structures," Requirements for Conformity Assessment of Structural Components, 2012. 
[8] G. Amato, V. Badalamenti, P. Colajanni, and L. La Mendola, Comportamento ciclico delle connessioni tra travi prefabbricate reticolari miste e pilastri in c.a.,pp. 3-12, 18 Congresso C.T.E. Brescia, Bologna, Italy, 2010.

[9] C. Mazzotti, L. Vincenzi, M. Savoia, and M. Ferrari, Comportamento di nodi trave-colonna di strutture parzialmente prefabbricate, pp. 255-265, 18 Congresso C.T.E. Brescia, Bologna, Italy, 2010.

[10] EN 10025:2005 "Hot Rolled Products of Structural Steels. Part 2: Technical Delivery Conditions for Non-alloy Structural Steels".

[11] G. Quaranta, F. Petrone, G. C. Marano, F. Trentadue, and G. Monti, "Structural design of composite concrete-steel beams with spatial truss reinforcement elements," Asian Journal of Civil Engineering (Building and Housing), vol. 12, no. 2, pp. 155-178, 2011.

[12] H. P. K. Manik, N. Paul, and S. Rahman, "Effect of welding on the properties of Mild steel \& cast iron specimen," International Conference on Mechanical, Industrial and Energy Engineering 2012, vol. 01-02, 2013.

[13] J. Nikolaou and G. D. Papadimitriou, "Mechanical properties of lap-welded reinforcing steel bars used for repairing damaged reinforced concrete structures," Materials and Structures, vol. 37, no. 10, pp. 698-706, 2004.

[14] T. Moustafa, W. Khalifa, M. R. El-Koussy, and N. Abd ElReheem, "Optimizing the welding parameters of reinforcing steel bars," Arabian Journal for Science and Engineering, vol. 41, no. 5, pp. 1699-1711, 2016.

[15] C. A. Issa and A. Nasr, "An experimental study of welded splices of reinforcing bars," Building and Environment, vol. 41, no. 10, pp. 1394-1405, 2006.

[16] C. A. Apostolopoulos, D. Michalopoulos, and L. Dimitrov, "The impact of corrosion on the mechanical behavior of welded splices of reinforcing steel S400 and B500c," Journal of Materials Engineering and Performance, vol. 17, no. 1, pp. 70-79, 2008.

[17] P. Riva, A. Franchi, and D. Tabeni, "Welded Tempcore reinforcement behaviour for seismic applications," Materials and Structures, vol. 34, no. 4, pp. 240-247, 2001.

[18] J. P. F. Lourenco, Study of Steel Bars for Use in Reinforced Concrete Produced by the "Tempcore" process: Master Degree Thesis, Instituto Superior Tecnico, Lisboa, Portugal, 2012.

[19] UNI EN ISO 15630-1:2019 “Acciaio per calcestruzzo armato e calcestruzzo armato precompresso - Metodi di prova - Parte 1: Barre, rotoli e fili per calcestruzzo armato".

[20] UNI EN ISO 6892-1:2016 "Materiali metallici - Prova di trazione - Parte 1: Metodo di prova a temperatura ambiente". 